\title{
Factors predicting 6-month retention among people with opioid use disorders accessing outpatient methadone maintenance therapy in Tshwane, South Africa
}

\author{
N R Gloeck, ${ }^{1,2}$ MB ChB, DTM\&H, MSc (Clinical Epidemiology); B N Harris, ${ }^{1}$ MB ChB, MMed (Comm Health); \\ E M Webb, ${ }^{1}$ BSc Agric (Genetics), BSc Agric Hons (Genetics), MPH, PhD (Epidemiology); A Scheibe, ${ }^{2}$ MB ChB, MPH \\ ${ }^{1}$ School of Health Systems and Public Health, Faculty of Health Sciences, University of Pretoria, South Africa \\ ${ }^{2}$ Community Oriented Substance Use Programme, Department of Family Medicine, Faculty of Health Sciences, University of Pretoria, South Africa
}

Corresponding author: N R Gloeck (natasha.gloeck@up.ac.za)

\begin{abstract}
Background. In South Africa (SA), increasing illicit opioid use and associated health challenges can be managed with opioid substitution therapy (OST), such as methadone, if the recommended dose and duration of use are prescribed. The Community Oriented Substance Use Programme (COSUP) provides free methadone to patients with opioid use disorder in Tshwane, SA, on need-based criteria.

Objectives. To determine selected sociodemographic and substance use treatment factors associated with retention for at least 6 months among participants receiving methadone as part of OST in COSUP.

Methods. This was a retrospective cohort study using secondary data of patients treated with methadone at 8 COSUP sites. The factors associated with at least 6 months' retention for 575 participants from December 2016 to September 2018 were analysed.

Results. There were $91.3 \%$ males, $86.4 \%$ South Africans and $85.9 \%$ black Africans, with a median age of 30 years. At baseline, the majority were injecting heroin (55.5\%) and were provided with free methadone (59.3\%). The median dose of methadone at 6 months or on leaving the programme was $20 \mathrm{mg} ; 38.4 \%$ of participants were retained for at least 6 months. Of those not retained, the median duration on methadone was 56 days, whereas for those retained for at least 6 months, the median number of days on methadone were 254 . After adjusting for sex and age, participants receiving methadone doses $<50 \mathrm{mg}$ had lower odds of being retained ( 0 - $20 \mathrm{mg}$ : adjusted odds ratio (aOR) $0.25 ; p=0.002 ; 95 \%$ confidence interval (CI) 0.10 - $0.61 ;>20$ - $40 \mathrm{mg}$ : aOR $0.20 ; p<0.001 ; 95 \%$ CI 0.08 - 0.49 ) than those administered $\geq 50 \mathrm{mg}$. Participants who received free methadone had 3.75 the odds of being retained than those buying it themselves $(p<0.001 ;$ 95\% CI 2.47 - 5.70). Participants treated in the inner city had 5.19 the odds of being retained than those in a suburban setting ( $p<0.001$; $95 \%$ CI 2.99 - 9.03). Compared with black African participants, white participants had 3.39 the odds of being retained ( $p=0.001$; 95\% CI $1.64-7.00$ ). Injecting heroin users had 0.63 the odds of being retained ( $p=0.032 ; 95 \%$ CI $0.41-0.96$ ).

Conclusions. To maximise retention on OST, methadone should be free, with maintenance doses $>50 \mathrm{mg}$. Reasons for lower retention among participants from periurban settings, those who inject and those from previously disadvantaged racial groups need to be explored, and findings used to inform programming.
\end{abstract}

S Afr Med J 2021;111(1):68-73. https://doi.org/10.7196/SAMJ.2021.v11111.14884

The use of illicit heroin is a challenge in South Africa (SA) and worldwide. The World Drug Report 2019 states that 17.3\% of people treated for a drug problem in SA use heroin as their primary drug of choice. ${ }^{[1]}$ Globally, and in SA, cannabis is the most commonly used non-regulated drug, while opioids are associated with the most negative health impacts. ${ }^{[2]}$ Opioids were associated with $76 \%$ of drug-related deaths in $2015 .{ }^{[2]}$ Approximately $0.7 \%$ of the global population aged 15 - 64 years were estimated to have used opioids for non-prescription purposes in 2016. ${ }^{[2]}$ In SA, and more specifically in Tshwane, heroin is locally known as nyaope, which is smoked or snorted, and might be mixed with cannabis and various other ingredients. ${ }^{[3]}$ The management of opioid use disorder (OUD) involves a comprehensive approach. The World Health Organization (WHO) advocates an evidence-based approach with opioid substitution therapy (OST) as the recommended treatment for the management of OUD. ${ }^{[4]}$ Methadone, a full $\mu$-opioid receptor agonist, and buprenorphine, a partial $\mu$-opioid receptor agonist (with or without naloxone, an opioid antagonist), are included in the WHO's essential drug list for OST. ${ }^{[5]}$

In 2016, in response to the growing prevalence of heroin use in Tshwane, in a joint initiative the City of Tshwane and the
Department of Family Medicine, University of Pretoria developed the Community Oriented Substance Use Programme (COSUP). ${ }^{[6]}$ COSUP was based on the principles of community-orientated primary care. ${ }^{[7]}$ The programme follows a harm-reduction approach, offering OST, as well as psychosocial support and needle syringe programmes to outpatients at 17 different sites around the city. ${ }^{[8]}$ Sites are situated in the inner city of Tshwane, as well as in surrounding suburban and periurban areas. OST offered to those with an OUD primarily includes methadone ( $80 \%)$. Buprenorphine-naloxone is also offered, but was not the focus of this research.

In COSUP, the OST dosing approach includes daily directly observed treatment (DOT) with take-home doses on weekends, and once stable, OST is entrusted to a family member or support person to take home for longer periods of time. Before initiation on methadone, each patient has a psychosocial evaluation, a medical history is taken and an examination is done. Participants with a high-risk opioid use score $(\geq 27)$ on the Alcohol, Smoking and Substance Involvement Screening Test (ASSIST 3.0), ${ }^{[9]}$ who are able to attend daily at a COSUP site and who do not have any medical contraindications to methadone, are initiated on OST. The ASSIST 3.0 is a tool developed by the WHO for primary healthcare settings 
where hazardous and harmful substance use among patients may go undetected. It is an 8-item questionnaire that determines a risk score for each substance used, i.e. low, moderate or high risk (the risk score determines the most appropriate intervention for that level of use). ${ }^{[9]}$

Methadone is prescribed by a medical doctor, and DOT is performed by a clinical associate. Patients are slowly up-titrated from their starting dose (average 10 - $30 \mathrm{mg} /$ day, with a standard starting dose of $20 \mathrm{mg}$ ), until they reach a maintenance dose, over 18 - 32 days. According to COSUP's standard operating procedure for OST, methadone should be increased by $5-10 \mathrm{mg}$ every 3 - 4 days, until a maintenance dose is reached. The dose is increased according to the patient's symptoms or experience of side-effects and clinician experience as per recommendations by the WHO. ${ }^{[4]}$ The dosage for self-funded patients is limited by their ability to pay.

After a need-based assessment, which includes medical and psychosocial investigations with home visits and assessment of either the financial ability to cover methadone costs, or urgency for which the client needs OST, those who are unable to pay are given methadone, funded by COSUP.

Internationally, it has been shown that prolonged methadone use within an OST programme decreases HIV and hepatitis C transmission, leads to a decrease in criminal activity and to an improvement in antiretroviral treatment (ART) adherence in people living with HIV. ${ }^{[10,11]}$ It is therefore important to retain patients in OST programmes. A factor associated with such retention is an adequate daily dose of methadone $(60-120 \mathrm{mg}){ }^{[3,4,12-14]}$ Other factors positively associated with being retained on OST include access to free or affordable OST medications, age $>35$ years, female sex, a higher level of education and being employed. Factors negatively associated with retention are the presence of a criminal record, serious mental illness and living in a rural area, where health services may be less accessible. ${ }^{[13,15-17]}$ A study of a pilot programme in Western Cape Province, using time-limited (3 months) buprenorphine-naloxone v. no buprenorphine-naloxone, showed that patients receiving the former were more likely to be retained in a substance use treatment programme than those not on the medication. ${ }^{[18]}$

The aim of this research was to determine selected sociodemographic and substance use treatment factors associated with retention for at least 6 months among participants receiving methadone as part of OST in COSUP.

\section{Methods}

This was a retrospective cohort study, including all patients enrolled into COSUP and initiated on methadone from December 2016 to September 2018. Participants from 8 COSUP and satellite sites were included, with complete sampling.

Inclusion criteria included: patients enrolled into COSUP at 1 of 8 sites or satellite sites during the study period, who signed consent and were started on methadone. Exclusion criteria included: COSUP patients not on OST or who were on buprenorphine (with/without naloxone). Patients who were receiving methadone at the end of the study period, but had not yet been using it for 6 months, were also excluded.

Data were abstracted from two sources. The first source comprised COSUP OST records kept by each site and updated every month. Data extracted were sex, location (inner city v. suburban), method of drug use at OST initiation, OST initiation date, methadone dose when starting and at 6 months or on leaving COSUP if before 6 months, total days on methadone, methadone funding source and termination date. The second data source comprised electronic patient records from Synaxon (Synaxon, SA), a health record database contracted by the Department of Family Medicine, University of Pretoria. Data extracted from this source were age, population group (black, white, coloured or Asian/Indian) and nationality. After using medical record numbers to connect patients to their records in both data sources and combining these, each participant was allocated a unique identifier that could not be connected to any identifying information. The data were imported into Stata 15 (StataCorp., USA) ${ }^{[19]}$ for analysis.

Descriptive statistics (mean, median, proportion, standard deviation (SD) and interquartile range (IQR))) were used to describe the population. The outcome variable was 'retained', where participants were defined as retained if receiving methadone for $\geq 6$ months after initiation date.

Continuous variables (e.g. age and methadone dosage) were explored graphically. An ordinal categorical variable for methadone dose was generated. The lower two categories were 0 - $20 \mathrm{mg}$ and $>20$ $40 \mathrm{mg}$, according to the most common dose used in participants. The highest category was $50-100 \mathrm{mg}$. No participants received $41-49 \mathrm{mg}$ methadone and, as such, this bracket was excluded. Ideally, the highest category should have been $80-120 \mathrm{mg}$, which is the international benchmark, ${ }^{[4]}$ but due to a limited number of participants in this group, a dose of $\geq 50 \mathrm{mg}$ was decided on as an appropriate marker to compare a higher dose with lower doses in the majority of participants.

Univariate analysis was performed for all variables. A $p$-value $\leq 0.25$ was used to identify variables for inclusion in the multivariate model. ${ }^{[20]}$ Bivariate analysis with Pearson's $\chi^{2}$-squared tests was performed to review associations between independent categorical variables.

A hierarchical backwards stepwise approach was used in trimming the multivariate model with likelihood ratio tests. Variables were kept in the model if $p \leq 0.2^{[21]}$ or if they were known independent factors influencing retention.

\section{Ethical approval}

The research was approved by the Health Sciences Research Ethics Committee, University of Pretoria (ref. no. 176/2019). Informed consent was obtained by COSUP staff when participants entered the programme. Participants did not receive remuneration on admission to COSUP.

\section{Results}

During the study period, 805 patients were initiated on methadone across the 8 sites. All patients provided informed consent for research participation. At the end of the study period, 230 patients had not yet received OST for 6 months.

Therefore, 575 participants were included in the analysis $(71.4 \%$; 575/805), and 221 (38.4\%) received methadone for at least 6 months. The median duration for those retained on methadone was 254 (IQR 215 - 352) days. The retained participants were 89.6\% ( $n=198)$ male, $80.5 \%(n=178)$ black African and $80.5 \%(n=178)$ South African. The most common method of drug use for this group was smoking (55.7\%; $n=123)$.

The median age of participants in the not-retained group was 30 (IQR 27 - 34) years, with a median methadone dose of 20 (IQR 20 $30) \mathrm{mg}$ at the time of leaving COSUP. The median duration for those not retained was 56 (IQR 27 - 109) days. Participants not retained were $92.4 \%(n=327)$ male, $89.3 \%(n=316)$ black African and $90.1 \%$ $(n=319)$ South African. Most $(55.4 \% ; n=196)$ participants reported smoking heroin at initiation. Further details are set out in Table 1.

Results for univariate and multivariate models after binary logistic regression for retained participants as the outcome are summarised in Table 2. For the final multivariate model, when adjusting for age, sex and injecting status, participants who were COSUP funded 


\begin{tabular}{|c|c|c|c|}
\hline Variable & Not retained & Retained & Total \\
\hline Participants, $n$ (\%) & $354(61.6)$ & $221(38.4)$ & $575(100)$ \\
\hline Age (years), median (IQR) & $30(27-34)$ & $30(27-35)$ & $30(27-34)$ \\
\hline \multicolumn{4}{|l|}{ Sex, $n(\%)$} \\
\hline Male & $327(92.4)$ & $198(89.6)$ & $525(91.3)$ \\
\hline Female & $27(7.6)$ & $23(10.4)$ & $50(8.7)$ \\
\hline \multicolumn{4}{|l|}{ Nationality, $n(\%)$} \\
\hline South African & $319(90.1)$ & $178(80.5)$ & $497(86.4)$ \\
\hline Foreign & $35(9.9)$ & $43(19.5)$ & $78(13.6)$ \\
\hline \multicolumn{4}{|l|}{ Population group, $n$ (\%) } \\
\hline Black & $316(89.3)$ & $178(80.5)$ & $494(85.9)$ \\
\hline White & $21(5.9)$ & $27(12.2)$ & $48(8.3)$ \\
\hline Coloured & $12(3.4)$ & $15(6.8)$ & $27(4.7)$ \\
\hline Indian & $5(1.4)$ & $1(0.5)$ & $6(1.0)$ \\
\hline Methadone dose $(\mathrm{mg})$, median (IQR)* & $20(20-30)$ & $30(20-40)$ & $20(20-30)$ \\
\hline Methadone (days), median (IQR) & $56(27-109)$ & $254(215-352)$ & - \\
\hline \multicolumn{4}{|l|}{ Funding, $n(\%)$} \\
\hline COSUP funded & $169(47.7)$ & $172(77.8)$ & $341(59.3)$ \\
\hline Self-funded & $185(52.3)$ & $49(22.2)$ & $234(40.7)$ \\
\hline \multicolumn{4}{|l|}{ Method of heroin use at initiation, $n$ (\%) } \\
\hline Smoke & $196(55.4)$ & $123(55.7)$ & $319(55.5)$ \\
\hline Inject & $158(44.6)$ & $98(44.3)$ & $256(44.5)$ \\
\hline
\end{tabular}

Table 2. Logistic regression results for OST retention, Tshwane, SA, December 2016 - September 2018

\begin{tabular}{|c|c|c|c|c|c|}
\hline \multirow[b]{2}{*}{ Covariables } & \multicolumn{2}{|c|}{ Univariate OR } & \multicolumn{3}{|c|}{ Multivariate aOR, $N=575$} \\
\hline & OR & $p$-value ${ }^{*}$ & aOR & $p$-value ${ }^{\dagger}$ & 95\% CI \\
\hline \multicolumn{6}{|l|}{ Funding } \\
\hline Self-funded & Ref. & & & & \\
\hline COSUP funded & 3.84 & $<0.001$ & 3.75 & $<0.001$ & $2.47-5.70$ \\
\hline \multicolumn{6}{|l|}{ Location } \\
\hline Suburban & Ref. & & & & \\
\hline Inner city & 4.72 & $<0.001$ & 5.19 & $<0.001$ & $2.99-9.03$ \\
\hline \multicolumn{6}{|l|}{ Dose category, mg } \\
\hline$\geq 50$ & Ref. & & & & \\
\hline $0-20$ & 0.17 & $<0.001$ & 0.25 & 0.002 & $0.10-0.61$ \\
\hline$>20-40$ & 0.23 & $<0.001$ & 0.20 & $<0.001$ & $0.08-0.49$ \\
\hline \multicolumn{6}{|l|}{ Nationality } \\
\hline South African & Ref. & & & & \\
\hline Foreign & 2.20 & 0.001 & - & - & - \\
\hline \multicolumn{6}{|l|}{ Population group } \\
\hline Black African & Ref. & & & & \\
\hline White & 2.28 & 0.007 & 3.39 & 0.001 & $1.64-7.00$ \\
\hline Coloured & 2.22 & 0.045 & 2.30 & 0.062 & $0.96-5.51$ \\
\hline Indian & 0.36 & 0.346 & 0.39 & 0.403 & $0.04-3.58$ \\
\hline Age, years & 1.02 & 0.088 & 1.01 & 0.470 & $0.98-1.04$ \\
\hline \multicolumn{6}{|l|}{ Sex } \\
\hline Male & Ref. & & & & \\
\hline Female & 1.41 & 0.254 & 0.80 & 0.526 & $0.40-1.60$ \\
\hline Injecting & 0.99 & 0.946 & 0.63 & 0.032 & $0.41-0.96$ \\
\hline
\end{tabular}


had 3.75 the odds of being retained compared with those who were self-funded ( $p<0.001 ; 95 \%$ confidence interval (CI) 2.48 - 5.70). Those treated in the inner city had 5.19 the odds of being retained compared with those who were treated in suburban sites $(p<0.001$; $95 \%$ CI 2.99 - 9.03). Compared with methadone doses $\geq 50 \mathrm{mg}$, those receiving $0-20 \mathrm{mg}$ had 0.25 the odds of being retained, and those on $>20-40 \mathrm{mg}$ had 0.20 the odds of being retained ( $p=0.002$; $95 \%$ CI $0.10-0.61$, and $p<0.001 ; 95 \%$ CI $0.08-0.49$, respectively). Compared with black African participants, white participants had 3.39 the odds of being retained ( $p=0.001 ; 95 \%$ CI $1.64-7.00$ ). Participants who reported injecting heroin at initiation had 0.63 the odds of being retained compared with those who smoked heroin ( $p=0.032 ; 95 \%$ CI $0.41-0.96$ ).

\section{Discussion}

Factors associated with retention in COSUP were access to funded methadone, methadone dose $\geq 50 \mathrm{mg}$, accessing treatment in the inner city, and white population group. Injecting drug use was negatively associated with retention. Age and sex were not associated with retention.

In accordance with the international literature, ${ }^{[13,15]}$ the availability of affordable (in our case, free) methadone was shown to play a significant role in retaining patients in OST programmes. The results show that patients receiving programme-funded methadone have 3.75 times the odds of staying on methadone for at least 6 months than those who buy their own methadone. This may be as a result of patients having limited funds and competing priorities, such as housing or food, on which to spend their money. ${ }^{[22]}$

The majority of South Africans access healthcare through the public health system, with $71.5 \%$ of households primarily accessing such facilities for their health needs. ${ }^{[23]}$ Care at government primary healthcare facilities, including prescription medication, is free of charge. Methadone, however, is not yet on the Essential Medicines List (EML) ${ }^{[24]}$ for use at the primary care level for maintenance. The cost of methadone in SA is $10-20$ times more than the average cost in other middle-income countries ${ }^{[25]}$ (ZAR0.81 - ZAR1.04 per mg, or ZAR40.50 - ZAR52.00 for a daily dose of $50 \mathrm{mg}$ ). ${ }^{[26]}$ Few people who use heroin are able to afford this expense. Making methadone accessible at a primary care level to people who use drugs, would assist them in regaining functional lives, with an overall improvement in their quality of life. ${ }^{[27]}$

Although almost none of the study participants was on optimal methadone doses according to WHO guidelines, ${ }^{[4]}$ and even local guidelines, ${ }^{[3]}$ it was clear that those administered doses $<50 \mathrm{mg}$ had lower odds of being retained. Lower doses of methadone might increase the likelihood of the co-use of illicit opioids ${ }^{[28,29]}$ to prevent withdrawal symptoms. Furthermore, suboptimal doses do not provide adequate receptor coverage, which is needed to reduce cravings. ${ }^{[25]}$ As such, it is unsurprising that participants who were not retained were more commonly on lower doses of methadone. Programmatically, one should take cognisance of this important outcome. International and local guidelines, ${ }^{[3,4]}$ as well as COSUP's OST standard operating procedure document, recommend that methadone be increased by $5-10 \mathrm{mg}$ every $3-5$ days until a maintenance dose is reached. The literature shows that the optimal maintenance dose is most commonly between $60 \mathrm{mg}$ and $120 \mathrm{mg}$ daily. ${ }^{[3,4]}$ The group not retained received methadone for a median duration of 56 (IQR 27 109 ) days. For that group, the median methadone dose was 20 (IQR 20 - 30) $\mathrm{mg}$, which is the recommended starting dose. Given that the majority of patients should have reached maintenance around 32 days if up-titrated according to guidelines, it points to the importance of intentional up-titration until maintenance is reached.
Even in the retained group, who were on methadone for a median of 254 (IQR 215 - 352) days, the majority of methadone doses remained below the recommended maintenance dose, with those on $\geq 50 \mathrm{mg}$ having greater odds of being retained. Patients are unlikely to remain in OST programmes if they do not receive appropriate doses. Over time, as they find they still need heroin to manage their cravings and because of withdrawal symptoms, they may lose faith in the programme and drop out. Furthermore, the time required to mobilise resources to secure methadone and/or heroin may make it challenging to access daily doses.

Reasons for prescribing suboptimal methadone dosing need to be explored through further research. Hypotheses from the literature are discussed below. Firstly, there is the fear of liability, where prescribers were concerned about possible overdose, especially with co-use of heroin during the first few weeks of methadone initiation. ${ }^{[30]}$ Prescribers may also not have had adequate training or experience in prescribing or managing patients on methadone and are therefore careful with prescription of doses. ${ }^{[31]}$ Secondly, there are unclear management goals, where a poor understanding of harm reduction may result in scepticism towards the need to prescribe methadone for long periods, as well as weaning patients off methadone to save them from daily clinic visits. ${ }^{[30]}$ Thirdly, there may be poor patienthealthcare worker communication, where patients do not feel free to admit co-use of a drug(s), and the prescriber is therefore not aware that the current methadone dose is not yet effective. Conversely, the prescriber may feel that the patient is trying to manipulate higher doses for personal gain, unrelated to the management of OUD, and therefore refuse to increase the dose. ${ }^{[30]}$ Finally, there are side-effects with higher doses, where prescribers found that participants had more side-effects, such as constipation, erectile dysfunction, sleeping problems and menstrual cycle irregularities, and therefore tapered the dose to mitigate these effects. ${ }^{[30]}$

It is interesting that participants frequenting inner-city sites have higher odds of being retained than those in suburban sites. Various hypotheses may be put forward. It may be due to the high prevalence of homelessness in the inner city, ${ }^{[22]}$ with participants motivated to access care and escape from their difficult circumstances. People living in suburban areas may be more likely to live at home. However, homelessness is not restricted to the inner city and further research is required in this regard. Another hypothesis is that the inner city is geographically a smaller area, which is fairly well serviced by 3 COSUP sites. It is possibly easier for participants to access these sites than for those in suburban areas, who may need to use transport, such as minibus taxis, to visit a site. It is possible that people from disadvantaged communities may have barriers to accessing care, including financial difficulties, where high costs associated with public transport, together with a potential loss of income associated with visiting a site, may deter participants from accessing care. ${ }^{[32]}$ While COSUP has attempted to ameliorate this situation by establishing sites in disadvantaged suburban areas, these cover a large geographical area. Another hypothesis is that there has already been harm reduction for people who have been using drugs in the city centre for a number of years - they may be more sensitised to this and more willing to access care. ${ }^{[33]}$

The mean methadone dose for those in the inner city was $37.8 \mathrm{mg}$ and for suburban areas $24.2 \mathrm{mg}$, with $55.9 \%$ injectors in the inner city and $41.6 \%$ injectors in the suburban area. This higher average dose at inner-city sites than at suburban sites may be the reason for better retention at the former. However, with the injecting of heroin negatively related to retention, this may not be true and should be further investigated. 
The majority of participants who are enrolled into COSUP are black Africans. Nonetheless, the results showed that white participants were more likely to be retained. The results for the coloured and Indian population groups were not significant, possibly because of the small number in each of these groups. The result may speak to the persisting disparity and socioeconomic inequality that are linked to race in SA, where white people have relatively better access to resources and are more empowered to use them than many of the other population groups. ${ }^{[34]}$ However, studies in the USA showed that communities generally view white drug users with more sympathy, assuming a valid reason for their drug use. There is a greater willingness to assist them with healthcare and resources than their counterparts from other racial groups. ${ }^{[35]}$ However, it is difficult to draw conclusions around this result, owing to factors regarding health inequality and other socioeconomic factors not examined in this study, which are discussed below under study limitations.

This research contributes to the body of knowledge surrounding illicit opioid use in SA. It will assist to enhance retention in OST programmes locally and beyond. Methadone should be made available on the primary care EML for OST as maintenance - at an affordable price.

Due to the secondary nature of the data, there were many areas that were not available for analysis. A follow-up study should take place investigating factors such as level of education, employment, social support systems, criminal records and other psychosocial factors, specifically in the SA context, which may contribute to retention. Going forward, information around education, employment and other psychosocial factors should be included as part of the programme data.

\section{Study strengths and limitations}

Strengths of this study include that it is an important and relevant topic in the SA context and unique in identifying issues within the SA health system regarding data that have not been available in the past. Results may allow for important service planning for this group of people.

Limitations of the study include that, using an approach of the last observation carried forward, and that all starting doses of methadone are low, it may be that had patients not dropped out, they would have ended on an optimal (higher) dose. This may introduce confounding but, given that there was an adequate number of days that patients received methadone for the majority to be on maintenance doses, this remains an important observation. A further limitation mentioned in relation to the differing retention among different race groups is that informed conclusions cannot be drawn around reasons for the result. While it is common practice to adjust for sociodemographic characteristics in multivariate analysis, important socioeconomic factors, such as dwelling, employment and education, as well as those around health inequality and different ethical views regarding substance use disorders, were not collected in this secondary dataset. Therefore, further research would be required to adequately delve into the reason for this result.

\section{Conclusions}

In this study, methadone dose, affordable methadone (free), treatment in the inner city and mode of heroin use were related to retention.

To improve retention, service improvements should include actively providing free methadone to people with OUD, and ensuring that doses comply with international standards. The introduction of methadone in the primary care EML would go a long way towards providing methadone to those in need. Furthermore, intentional up-titration of methadone, as recommended in guidelines, should be a priority to ensure that maintenance doses are reached in a safe and timely manner, with a knock-on effect of higher doses, thus aligning with international standards. People who inject opioids should remain a priority in methadone maintenance programmes, focusing on the abovementioned areas to keep them retained. More research is required to understand why inner-city participants are more likely to be retained in treatment, as well as to better understand the difference in retention with regard to different racial groups.

\section{Declaration. None.}

Acknowledgements. We thank COSUP participants and staff and the relevant staff at the Department of Family Medicine, University of Pretoria, for allowing the use of secondary data. We also thank Prof. Brendan GirdlerBrown for statistical advice.

Author contributions. NRG developed the study protocol, collated and analysed the data, and wrote the manuscript. BNH contributed to the study protocol, and writing, reviewing and editing of the manuscript. EMW contributed to writing, reviewing and editing of the manuscript. AS advised on data analysis and contributed to writing, reviewing and editing of the manuscript.

Funding. None.

Conflicts of interest. None.

1. United Nations Office on Drugs and Crime. World Drug Report. 2019. https://wdr.unodc.org/wdr2019/ index.html (accessed 1 October 2019).

2. United Nations Office on Drugs and Crime. World Drug Report. 2018. https://www.unodc.org/wdr2018/ (accessed 26 September 2019).

3. Weich L. South African guidelines for the management of opioid use disorders. South African Addiction Medicine Society. 2015. https://www.saams.co.za/OpManCourse/Guidelines (accessed 1 October 2018). 4orld Health Organization. Guidelines for the Psychosocially Assisted Pharmacological Treatment of Opioid Dependence. Geneva: WHO, 2009

5. World Health Organization. Clinical guidelines for withdrawal management and treatment of drug

World Health Organization. Clinical guidelines for withdrawal management and treatment of drug
dependence in closed settings. 2009. https://www.who.int/hiv/pub/idu/wpro_withdrawl/en/ (accessed 7 July 2019).

6. Hugo J, Marcus T, Shange L, Shelly S, Scheibe A, Kroukamp L. Researching the Development, Application and Implementation of a Community Oriented Substance Use Programme (COSUP) Protocol. Pretoria University of Pretoria, 2017.

7. Marcus T. COPC - A Practical Guide. Pretoria: Department of Family Medicine, University of Pretoria, 2018.

8. Scheibe A, Shelly S, Hugo J, et al. Harm reduction in practice - the Community Oriented Substance Use Programme in Tshwane. Afr J Prim Health Care Fam Med 2020;12(1):2285. https://doi.org/10.4102/ phcfm.v12i1.2285

9. World Health Organization. The alcohol, smoking and substance involvement screening test. 2010 https://www.who.int/substance_abuse/activities/assist/en/ (accessed 15 July 2019).

10. Brady TM, Salvucci S, Sverdlov LS, et al. Methadone dosage and retention: An examination of the $60 \mathrm{mg} /$ day threshold. J Addict Dis 2005;24(3):23-47. https://doi.org/10.1300/J069v24n03_03

11. Parashar S, Collins AB, Montaner JSG, Hogg RS, Milloy M-J. Reducing rates of preventable HIV/ . Parashar S, Collins AB, Montaner JSG, Hogg RS, Milloy M-J. Reducing rates of preventable HIV/
AIDS-associated mortality among people living with HIV who inject drugs. Curr Opin HIV AIDS 2016;1(5):507-513. https://doi.org/10.1097/COH.0000000000000297

12. Faggiano F, Vigna-Taglianti F, Versino E, Lemma P. Methadone maintenance at different dosages for opioid dependence. Cochrane Database Syst Rev 2003;(3):CD002208. https://doi.org/10.1002/14651858 CD002208

13. Proctor SL, Copeland AL, Kopak AM, Hoffmann NG, Herschman PL, Polukhina N. Predictors of patient retention in methadone maintenance treatment. Psychol Addict Behav 2015;29(4):906-917. https://doi org/10.1037/adb0000090

14. Connery HS. Medication-assisted treatment of opioid use disorder. Harv Rev Psychiatry 2015;23(2):63-75. https://doi.org/10.1097/HRP.0000000000000075

15. Zhou K, Zhuang G. Retention in methadone maintenance treatment in mainland China, 2004 - 2012 A literature review. Addict Behav 2014;39(1):22-29. https://doi.org/10.1016/j.addbeh.2013.09.001

16. Sarasvita R, Tonkin A, Utomo B, Ali R. Predictive factors for treatment retention in methadone programs 6. Sarasvita R, Tonkin A, Utomo B, Ali R. Predictive factors for treatment retention in methadone proge
in Indonesia. J Subst Abuse Treat 2012;42(3):239-246. https://doi.org/10.1016/.j.jat.2011.07.009

17. Yang F, Lin P, Li Y, et al. Predictors of retention in community-based methadone maintenance treatment program in Pearl River Delta, China. Harm Reduct J 2013;10:3. https://doi.org/10.1186/1477-7517-10-3 18. Michie G, Hoosain S, Macharia M, Weich L. Report on the first government-funded opioid substitution programme for heroin users in the Western Cape province, South Africa. S Afr Med J 2017;107(6):539-542 https://doi.org/10.7196/SAMJ.2017.v107i6.12140

19. StataCorp. Stata statistical software: Release 15. Texas: StataCorp., 2017.

20. Hilbe J. Logistic Regression Models. 1st ed. Florida: Chapman and Hall/CRC, 2009.

21. Hosmer DW, Lemeshow S, Sturdivant RX. Applied Logistic Regression. 3rd ed. New Jersey: Wiley, 2013.

22. Renkin W. Finding a prophetic response to end homelessness in the city of Tshwane: A transdisciplinary approach. MDiv thesis. University of Pretoria. 2015. https://doi.org/10.13140/RG.2.2.10539.44325

23. Statistics South Africa. General Household Survey. Pretoria: Stats SA, 2018. http://www.statssa.gov.za/ publications/P0318/P03182018.pdf (accessed 10 October 2019).
Statistics South Africa. General Househol Surve. Pretoria: Sta 24. National Department of Health. Standard Treatment Guidelines and Essential Medicines List for South
Africa: Primary Healthcare Level. 6th ed. Pretoria: NDoH, 2018. 
25. Scheibe A, Marks M, Shelly S, Gerardy T, Domingo AK, Hugo J. Developing an advocacy agenda for increasing access to opioid substitution therapy as part of comprehensive services for people who
use drugs in South Africa. S Afr Med J 2018;108(10):800-802. https://doi.org/10.7196/FSAMJ.2018. use drugs in $\mathrm{s}$.
v108i10.13397

26. Health-E News. Medicine price registry. 2019. https://health-e.org.za/medicine-price-registry (accessed 15 October 2019).

27. Teoh Bing Fei J, Yee A, Habil MH, Danaee M. Effectiveness of methadone maintenance therapy and Teoh Bing Fei J, Yee A, Habil MH, Danaee M. Effectiveness of methadone maintenance therapy and
improvement in quality of life following a decade of implementation. J Subst Abuse Treat 2016;69:50-56. improvement in quality of life following a decade of implementation. J Subst Abuse Treat 2016;69:50-56 https://doi.org/10.1016/j.jsat.2016.07.006

28. Hartel DM, Schoenbaum EE, Selwyn PA, et al. Heroin use during methadone maintenance treatment The importance of methadone dose and cocaine use. Am J Public Health 1995;85(1):83-88. https:/ doi.org/10.2105/ajph.85.1.83

29. Strain EC, Bigelow GE, Liebson IA, Stitzer ML. Moderate- vs high-dose methadone in the treatment of opioid dependence: A randomized trial. JAMA 1999;81(11):1000-1005. https://doi.org/10.1001 jama.281.11.1000

30. Lin C, Detels R. A qualitative study exploring the reason for low dosage of methadone prescribed in the MMT clinics in China. Drug Alcohol Depend 2011;117(1):45-49. https://doi.org/10.1016\%2F drugalcdep.2011.01.004
31. Weich L, Perkel C, van Zyl N, Rataemane ST, Naidoo L. Medical management of opioid dependence in South Africa. S Afr Med J 2008;98(4):280-283. https://doi.org/10.7196/SAMJ.319

32. Myers BJ Louw J Pasche SC. Inequitable access to substance abuse treatment services in Cape Town, South Africa. Subst Abuse Treat Prev Policy 2010;5(1):28. https://doi.org/10.1186\%2F1747-597X-5-28 33. Dada S, Harker Burnhams N, Erasmus J, et al. Research brief: Monitoring alcohol, tobacco and other drug use trends in South Africa (July 1996 - December 2018): Phase 45. 2019. http://www.samrc.ac.za/ sites/default/files/attachments/2019-10-16/SACENDUBriefPhase45.pdf (accessed 10 October 2019). 34. Sanders D, Chopra M. Key challenges to achieving health for all in an inequitable society: The case of South Africa. Am J Publ Health 2006;96(1):73-78. https://doi.org/10.2105\%2FAJPH.2005.062679

35. Netherland J, Hansen HB. The war on drugs that wasn't: Wasted whiteness, 'dirty doctors', and race in media coverage of prescription opioid misuse. Cult Med Psychiatry 2016;40(4):664-686. https://doi. org/10.1007/s11013-016-9496-5

Accepted 11 November 2020 